\title{
Surfactant-assisted synthesis of pure calcium carbonate nanoparticles from Sri Lankan dolomite
}

\author{
M.M.M.G.P.G. Mantilaka ${ }^{1,2^{*}}$, W.P.S.L. Wijesinghe ${ }^{1,2}$, H.M.T.G.A. Pitawala ${ }^{1,3}$, R.M.G. Rajapakse ${ }^{1,2}$ \\ and D.G.G.P. Karunaratne ${ }^{1,4}$ \\ ${ }^{I}$ Postgraduate Institute of Science, University of Peradeniya, Peradeniya. \\ 2 Department of Chemistry, Faculty of Science, University of Peradeniya, Peradeniya. \\ ${ }^{3}$ Department of Geology, Faculty of Science, University of Peradeniya, Peradeniya. \\ ${ }^{4}$ Department of Chemical and Process Engineering, Faculty of Engineering, University of Peradeniya, Peradeniya.
}

\begin{abstract}
Sri Lanka is rich in extensive deposits of dolomitic marbles with large quantities, which have not yet been exploited on an industrial-scale to produce value-added products such as precipitated calcium carbonate (PCC) nanoparticles. PCC is used extensively and is imported by Sri Lankan industries for application as a filler and extender. Hence, this work attempts to examine Sri Lankan impure dolomitic marbles as a source for the synthesis of pure PCC nanoparticles, so as to fulfill the current industrial demand and to add value to the cheap and mundane marbles. As reported in this paper, the calcium (Ca) components of the marbles can be extracted from impurities by preparing solutions of saturated calcium hydroxide, calcium citrate, $\mathrm{Ca}^{2+}$-ethylenediaminetetraacetic acid complexes and calcium sucrate, separately from dolomite. PCC nanoparticles are then synthesized by adding sodium carbonate to each calcium extract. The results shows that the best extract to synthesize PCC nanoparticles with high yield and purity is calcium sucrate. Here, calcium sucrate has been used for surfactant assisted hydrothermal synthesis of PCC nanoparticles with particle sizes ranging from $38.9-51.6 \mathrm{~nm}$, which is a novel effort. This method could be applied to manufacture PCC nanoparticles on an industrial-scale.
\end{abstract}

Keywords: Calcite, calcium carbonate, dolomitic marble nanoparticles, precipitated calcium carbonate, value addition.

\section{INTRODUCTION}

Extensive deposits of crystalline limestones, which are also known as marbles cover over 20 percent of the land area of Sri Lanka (Cooray, 1984). These rocks with large quantities are only distributed in places of the Highland Complex such as Kandy, Matale, Nalanda, Habarana,
Badulla, Welimada and Balangoda (Cooray, 1984; Madugalla et al., 2013). Most of the Sri Lankan marbles contain dolomite as the major mineral (Cooray, 1984). The accessory minerals found in these rocks are calcite, apatite, spinel, phlogopite, olivine, pyrite and iron oxides (Madugalla et al., 2013). Throughout the world, marbles are of economical importance owing to their broad range of applications including preparation of dimensional or decorative stones, as a refractory material, as a catalyst, in the production of lime, as a fertilizer and as an additive in glass, paper, plastics and rubber industries (Varela et al., 2006; Rabaha \& Ewais, 2009; Sun et al., 2012; Karatas et al., 2013). These applications mainly depend on the grain size and purity of marbles (Varela et al., 2006). The high variability of chemical and mineralogical composition (Pitawala et al., 2003), high intensified fractures in the rock, coarse grained nature and higher quantities of impurities (Cooray, 1984; Madugalla et al., 2013) in Sri Lankan marbles makes it unsuitable for most of the above applications. Hence, the current use of Sri Lankan marbles is limited to the lime industry, construction activities and the production of fertilizers (Mantilaka et al., 2013a). However, based on the chemical composition, these rocks have a high potential to synthesize chemical products such as precipitated calcium carbonate (PCC), magnesium hydroxide, magnesium oxide and their nanomaterials (Mantilaka et al., 2013 a; b; 2014 a;b). Of these products, PCC has a high economic potential as it is in great demand in industries such as paper, textile, rubber, plastic, paint, cosmetic, sealant, tooth paste and food stuff (Kim et al., 2009; Price et al., 
2011; Yamanaka et al., 2012). Most of these industries are well established in Sri Lanka with large production capacities. Currently the demand for PCC in Sri Lankan industries is fulfilled by importing it from countries such as India, Malaysia and China at a high cost. However, the synthesis of PCC nanoparticles on an industrial scale has not yet been considered by the Sri Lankan industrialists despite the fact that several simple procedures have been documented by Mantilaka et al. (2013 b; 2014 a) and other researchers throughout the globe (El-Sheikh et al., 2013). Therefore, the synthesis of PCC from Sri Lankan marbles is timely and needed and it also serves as a move towards value-addition to a Sri Lankan resource. Furthermore, nanoparticles of PCC are much more attractive to industries than the conventional coarse PCC particles because of the dramatic increase in the surface area-to-volume ratio in the nanometer scale. This contributes to astonishing catalytic powers and extraordinary interactions between these filling materials and their host materials when the nanoparticles are used as fillers in various products such as paper, textiles, rubber, plastics, paints, cosmetics and sealants (Periago et al., 2010; El-Sheikh et al., 2013; Senarathna et al., 2014). PCC nanoparticles are very expensive when compared to conventional PCC products. Therefore, maximum valueaddition to Sri Lankan marbles can be accomplished through the manufacture of PCC nanoparticles and its use in industries. However, due to the dolomitic nature of Sri Lankan marbles, it is necessary to first extract and separate the calcium components from impurities prior to the synthesis of PCC nanoparticles (Mantilaka et al., 2013 b; 2014 a). Therefore, novel, simple and economical techniques to synthesize PCC nanoparticles from the Sri Lankan marbles are required.

The present study focused on three theoretically possible methods to extract the calcium components of dolomite in order to synthesize pure PCC nanoparticles. These methods were: (1) extraction of calcium components from dolomite into an aqueous solution through preparation of a saturated calcium hydroxide solution, (2) preparation of calcium citrate and calciumethylenediaminetetraacetic acid ( $\mathrm{Ca}^{2+}$-EDTA) complexes and (3) preparation of calcium sucrate by extracting calcium components to a sucrose solution. We have already documented the calcium sucrate method elsewhere (Mantilaka et al., 2013 b; 2014 a). Out of these possible methods, the best method that meets the requirements for industrializing the production process of PCC nanoparticles was selected.

The best and most suitable method to synthesize PCC is through calcium sucrate route since the productivity of this method is higher compared to the other methods.
Furthermore, the present study reports for the first time the synthesis of PCC nanoparticles through a surfactantassisted hydrothermal method, starting from calcium sucrate prepared using dolomite. This method can be applied to manufacture PCC nanoparticles on an industrial scale in an effort to fulfill the current demand for PCC nanoparticles in local industries as well as for value-addition to dolomitic marbles.

\section{METHODS AND MATERIALS}

\section{Materials}

Sodium carbonate, sucrose, ethylenediaminetetraacetic acid (EDTA), trisodium citrate dihydrate and Triton X-100 of analytical grade were purchased from SigmaAldrich. Dolomitic marble samples were collected from a working marble quarry located in the Naula area in Sri Lanka. These rock samples were crushed, ground and the sieved fraction less than $150 \mu \mathrm{m}$ was used for the synthesis. The powdered marble sample was heated at $900{ }^{\circ} \mathrm{C}$ for $3 \mathrm{~h}$ to produce calcined dolomite $(\mathrm{CaO}$. $\mathrm{MgO})$.

\section{Preparation of $\mathrm{PCC}$ from saturated $\mathrm{Ca}(\mathrm{OH})_{2}$ solution obtained from calcined dolomite}

A saturated solution of $\mathrm{Ca}(\mathrm{OH})_{2}$ was prepared by dissolving $0.265 \mathrm{~g}$ of calcined dolomite in $100.0 \mathrm{~mL}$ of distilled water and the mixture was stirred for $1 \mathrm{~h}$. The solution was separated from the precipitate by filtering. A sodium carbonate solution $(0.10 \mathrm{M}, 10.0 \mathrm{~mL})$ was added to the filtrate of saturated $\mathrm{Ca}(\mathrm{OH})_{2}$ solution to precipitate calcium carbonate. The PCC product was collected by filtering and the product thus obtained was dried in a vacuum oven at $45^{\circ} \mathrm{C}$ and $600 \mathrm{~mm} \mathrm{Hg}$ conditions for $12 \mathrm{~h}$.

\section{PCC nanoparticles from $\mathrm{Ca}^{2+}$ - ligand complexes}

Calcined dolomite $(0.50 \mathrm{~g})$ was added separately to trisodium citrate and EDTA $(100.0 \mathrm{~mL}$ of $0.50 \mathrm{M}$ each) solutions to produce calcium citrate and calcium EDTA complexes. The resulting solutions were collected by filtering. Sodium carbonate $(0.50 \mathrm{M}, 100 \mathrm{~mL})$ was added drop-wise to the calcium-ligand complexes in order to synthesize PCC. The PCC product was collected by filtering and dried in vacuum oven at $45^{\circ} \mathrm{C}$ and $600 \mathrm{~mm}$ $\mathrm{Hg}$ conditions for $12 \mathrm{~h}$.

\section{PCC nanoparticles using calcium sucrate solution}

Calcined dolomite $(5.00 \mathrm{~g})$ was added to $0.50 \mathrm{M}$ sucrose 
$(100.0 \mathrm{~mL})$ and stirred for $1 \mathrm{~h}$ to prepare a calcium sucrate solution. The resulting calcium sucrate solution was collected by filtering under suction. Triton X-100 $(0.50 \mathrm{~mL})$ was added to the calcium sucrate solution and stirred for $1 \mathrm{~h}$. A sodium carbonate solution $(0.50 \mathrm{M}$, $100.0 \mathrm{~mL}$ ) was added drop-wise to the reaction mixture while stirring in order to allow calcium carbonate to be precipitated. The precipitate was collected by centrifuging and dispersed in $30.0 \mathrm{~mL}$ of water. The dispersion was added to $50.0 \mathrm{~mL}$ Teflon-lined stainless steel autoclave for hydrothermal treatment at $160{ }^{\circ} \mathrm{C}$ for $15 \mathrm{~h}$. The synthesized PCC product was washed with $10.0 \mathrm{~mL}$ of ethanol and then with $50.0 \mathrm{~mL}$ of distilled water 3 times to remove the impurities including Triton X-100 and it was dried afterwards in a vacuum oven at $45^{\circ} \mathrm{C}$ and 600 $\mathrm{mm} \mathrm{Hg}$ conditions for $12 \mathrm{~h}$.

\section{Characterization}

The $\mathrm{Ca}^{2+}$ and $\mathrm{Mg}^{2+}$ contents of calcium citrate, saturated calcium hydroxide and calcium sucrate were measured using Buck Scientific 200-A atomic absorption spectrophotometer (AAS). X-ray diffraction (XRD) analysis was performed to identify the crystalline phases of the final PCC products from Siemens D5000 $\mathrm{X}$-ray powder diffractometer with $\mathrm{Cu} \mathrm{K \alpha}$ radiation of wavelength $\lambda=0.154 \mathrm{~nm}$ and scanning rate $2^{\circ} \mathrm{min}^{-1}$. The XRD patterns were analyzed with the aid of ICDD PDF 2 database. The average particle size of PCC products was estimated by means of the Debye-Scherrer formula using the full width of the half-maximum of the XRD major peaks. Morphology of the PCC was examined with the help of Hitachi SU6600 scanning electron microscope (SEM) at the acceleration voltage of $10 \mathrm{kV}$. The dynamic light scattering (DLS) particle size distribution curves of PCC nanoparticles prepared from calcium sucrate were obtained with the aid of CILAS Nano DS dual scattering particle size analyzer. The fourier transform infrared (FTIR) spectra of PCC products were recorded on Shimadzu IRPrestige 21 instrument with the $\mathrm{KBr}$ pellet method. Herein, $\mathrm{KBr}$ pellets were prepared by mixing the sample and $\mathrm{KBr}$ in the mass ratio of 1:40 and pressing the mixture by applying a pressure of 5 tons. Thermo gravimetric analysis (TGA) was performed using Scinco STA N-650 simultaneous thermal analyzer at a heating rate of $10^{\circ} \mathrm{C} / \mathrm{min}$ in the presence of air flow.

\section{RESULTS AND DISCUSSION}

\section{Characterization of dolomitic marbles}

The XRD pattern of dolomitic marble sample is given in Figure 1a. The XRD peaks of marble sample centered at $2 \theta$ values of $30.9^{\circ}, 41.1^{\circ}, 51.0^{\circ}$ and $64.5^{\circ}$ confirmed that the major mineral in the collected marble sample is dolomite (JCPDS card no. 84-1208). The TGA plot of the marble sample (Figure 1b) reveals a single-step decomposition with a mass loss of $40 \%$ in the temperature ranging from $673-788^{\circ} \mathrm{C}$, which is attributed to the decomposition of $\mathrm{CaMg}\left(\mathrm{CO}_{3}\right)_{2}$ to $\mathrm{CaO} . \mathrm{MgO}$ (Mantilaka et al., 2013b). This single step decomposition of dolomite takes place under atmospheric pressure conditions (Samtani et al., 2001). Based on the analyses, mass percentages of $\mathrm{CaCO}_{3}, \mathrm{MgCO}_{3}$ and impurities of the marble sample are $51.3,45.6$ and $3.1 \%$, respectively.

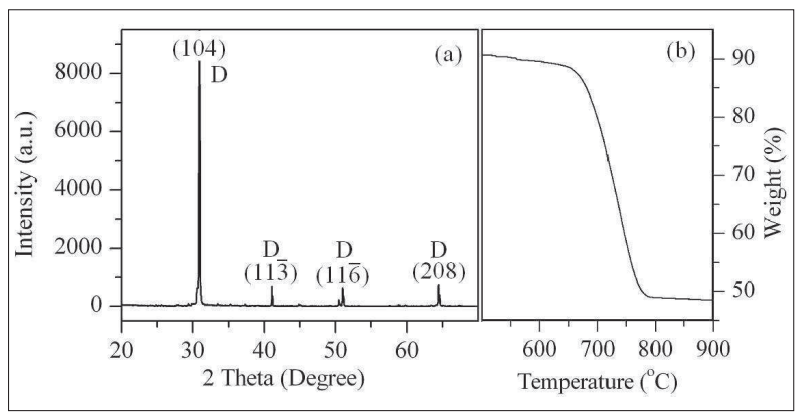

Figure 1: (a) XRD pattern; (b) TGA plot of the marble sample collected from Naula, Sri Lanka where, 'D' represents dolomite.

\section{Separation techniques of $\mathrm{Ca}^{2+}$ and $\mathrm{Mg}^{2+}$ from dolomite}

The first effort to extract $\mathrm{Ca}^{2+}$ in dolomite to synthesize PCC is through the preparation of a saturated $\mathrm{Ca}(\mathrm{OH})_{2}$ solution by dissolving calcined dolomite in water. The required calcined dolomite $(\mathrm{CaO} . \mathrm{MgO})$ content to prepare $100.0 \mathrm{~mL}$ of saturated $\mathrm{Ca}(\mathrm{OH})_{2}$, solution can be calculated by means of solubility product constant $\left(\mathrm{K}_{\mathrm{sp}}\right)$ of $\mathrm{Ca}(\mathrm{OH})_{2}\left(\mathrm{~K}_{\mathrm{sp}}=6.5 \times 10^{-6} \mathrm{~mol}^{3} \mathrm{dm}^{-9}\right.$ at $\left.25^{\circ} \mathrm{C}\right)$. In the hydration step of calcined dolomite, $\mathrm{MgO}$ component is converted to $\mathrm{Mg}(\mathrm{OH})_{2}$, which has a very low solubility $\left(\mathrm{K}_{\mathrm{sp}}=7.1 \times 10^{-12} \mathrm{~mol}^{3} \mathrm{dm}^{-9}\right.$ at $\left.25^{\circ} \mathrm{C}\right)$ than that of $\mathrm{Ca}(\mathrm{OH})_{2}$. Therefore, as calculated, more than $99.9 \%$ of $\mathrm{Mg}^{2+}$ ions of dolomite are precipitated under saturation conditions of $\mathrm{Ca}(\mathrm{OH})_{2}$.

In the second method, the $\mathrm{Ca}^{2+}$ content of dolomite is extracted to ligands of trisodium citrate and EDTA. These ligands form strong chelating complexes with $\mathrm{Ca}^{2+}$ ions (Jeffery et al., 1989; Xiang et al., 2002; Westin \& Rasmuson, $2005 \mathrm{a} ; \mathrm{b})$ and the complexes are generated by dissolving calcined dolomite in the aqueous solutions of these ligands. $\mathrm{Mg}^{2+}$ ions also form similar type of complexes with these ligands (Jeffery et al., 1989). However, the stability constants of each $\mathrm{Ca}^{2+}$ - 
ligand complexes are greater than that of their $\mathrm{Mg}^{2+}$ ligand complexes (Jeffery et al., 1989). Therefore, the formation of $\mathrm{Ca}^{2+}$-ligand complex is more favoured over that of the $\mathrm{Mg}^{2+}$-ligand complex. This concept is useful for the extraction of $\mathrm{Ca}^{2+}$ component of the dolomite to synthesize PCC through the extraction of $\mathrm{Ca}^{2+}$ as complexes.

In the third method, a sucrose solution is employed to extract $\mathrm{Ca}^{2+}$ component from the calcined dolomite. Herein, $\mathrm{CaO}$ of the calcined dolomite is allowed to react with sucrose to form water soluble calcium sucrate $(\mathrm{Wu}$ et al., 2007). $\mathrm{MgO}$ and other impurities in calcined dolomite do not react with sucrose and they will be present in the precipitated form (Seil, 1943; Mantilaka et al., 2013b). The AAS analysis performed to determine the amounts of $\mathrm{Ca}^{2+}$ and $\mathrm{Mg}^{2+}$ that may be present in the extractions reveal the following information. The $\mathrm{Ca}^{2+}$ and $\mathrm{Mg}^{2+}$ mol percentages, can be calculated using the following equation,

mol percentage $=\frac{\text { moles of } \mathrm{Ca}^{2+} \text { in the solution }}{\text { moles of } \mathrm{Ca}^{2+} \text { in the dolomitic marble }} \times 100 \%$

The $\mathrm{Ca}^{2+}$ and $\mathrm{Mg}^{2+}$ percentages of saturated $\mathrm{Ca}(\mathrm{OH})_{2}$, calcium citrate, $\mathrm{Ca}^{2+}$-EDTA complex and of calcium sucrate are tabulated in Table 1 . The remaining $\mathrm{Ca}^{2+}$ ions are present in the precipitated components of calcined dolomite. Therefore, in all these methods, the separation of $\mathrm{Mg}^{2+}$ from $\mathrm{Ca}^{2+}$ has been almost completely accomplished. However, the $\mathrm{Ca}^{2+}$ content extracted in the citrate solution has been very low compared to the other solutions because calcium citrate has a low watersolublity. Hence, the use of citrates to extract $\mathrm{Ca}^{2+}$ is not suitable to prepare PCC in industrial scale. The best method to separate $\mathrm{Ca}^{2+}$ and $\mathrm{Mg}^{2+}$ from dolomite is the method that involves the use of EDTA. However, the $\mathrm{Ca}^{2+}$-EDTA complex is highly stable due to the formation of hexadentate chelating complex (Jeffery et al., 1989; Xiang et al., 2002; Westin \& Rasmuson, 2005a;b). Therefore, even after adding $\mathrm{Na}_{2} \mathrm{CO}_{3}$ at different $\mathrm{pH}$ conditions it did not result in PCC. Based on AAS results, the use of saturated $\mathrm{Ca}(\mathrm{OH})$, solution and calcium sucrate was found to be the best $\mathrm{Ca}^{2+}$ sources to prepare PCC.

Table 1: $\mathrm{Ca}^{2+}$ and $\mathrm{Mg}^{2+}$ mol percentages of each calcium extraction based on AAS analysis

\begin{tabular}{lll}
\hline Calcium extraction & $\begin{array}{l}\mathrm{Ca}^{2+} \text { mol } \\
\text { percentage }\end{array}$ & $\begin{array}{l}\mathrm{Mg}^{2+} \text { mol } \\
\text { percentage }\end{array}$ \\
\hline & & \\
Saturated $\mathrm{Ca}(\mathrm{OH})_{2}$ & 77.0 & 0.64 \\
Calcium citrate & 26.0 & 0.04 \\
$\mathrm{Ca}^{2+}$-EDTA complex & 95.4 & 0.01 \\
Calcium sucrate & 87.0 & 0.18 \\
\hline
\end{tabular}

\section{XRD studies on PCC products}

The XRD patterns of PCC products synthesized from different methods are depicted in Figure 2. The XRD peaks of all patterns located at $2 \theta$ values of $23.0^{\circ}, 29.4^{\circ}$, $36.0^{\circ}, 39.4^{\circ}, 43.1^{\circ}, 47.4^{\circ}, 48.5^{\circ}, 56.5^{\circ}$ and $57.3^{\circ}$ reveal the presence of calcite as the only polymorphic form of $\mathrm{CaCO}_{3} \cdot \mathrm{CaCO}_{3}$ occurs in 3 polymorphic crystalline forms of calcite, vaterite and aragonite (Wang et al., 2013), out of which, calcite is the thermodynamically most stable form of $\mathrm{CaCO}_{3}$ (Park et al., 2008). The remaining less stable forms are not found in any of these synthesized products. Aragonite is usually found in PCCs synthesized at temperatures over $80^{\circ} \mathrm{C}$ (Wang et al., 2006; KonopackaŁyskawa \& Lackowski, 2011). However, it was not formed in the PCC synthesized using calcium sucrate at the high temperature used in this work. Hence, it can be concluded that the sucrose molecules have inhibited the formation of aragonite and have stabilized the calcite phase. The average crystallite sizes of PCC synthesized using calcium sucrate and calcium citrate solutions as estimated by Debye-Scherrer formula are 41 and $30 \mathrm{~nm}$, respectively. The particle sizes have been maintained in the nanoscale by sucrate and citrate together with Triton $\mathrm{X}-100$. Out of these additives, citrate is the best additive to keep the particles in nanoscale compared to Triton X-100 surfactant. The dispersivity of the resulting PCC particles has been improved by the negative charges of citrates (Leeuwenburgh et al., 2010). Therefore, the aggregation of PCC nanoparticles is prevented by citrate anions through electrostatic repulsions. Triton $\mathrm{X}-100$ also functions to prevent the aggregation of PCC nanoparticles during formation by covering the particles by the micelles of these amphiphilic molecules, which

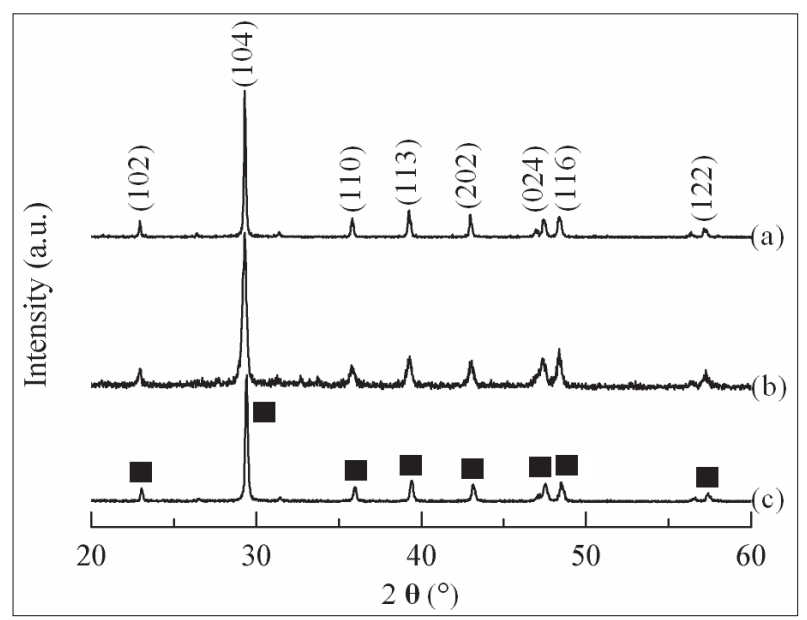

Figure 2: XRD patterns of PCC products prepared from (a) saturated solution of $\mathrm{Ca}(\mathrm{OH})_{2}$; (b) calcium cirate complex and (c) calcium sucrate where, ' $\boldsymbol{\omega}$ ' represents calcite. 
is commonly known as steric stabilization (Zhang et al., 2006; Li et al., 2010). However, the electrostatic forces are more effective than steric forces in the colloidal stabilization (Li et al., 2010). Hence, citrate has more ability to keep PCC particles in nanoscale than that of Triton X-100. Further particle aggregation can be prevented by hydrothermal treatment.

\section{FTIR studies of the PCC products}

FTIR results of the PCC products agree well with the XRD results. The FTIR bands of PCC products (Figure 3a, 3b, and $3 \mathrm{c}$ ) centered at 874 and $712 \mathrm{~cm}^{-1}$ reveal the presence of calcite (Sarkar \& Mahapatra, 2010; Yao et al., 2011; Zhao \& Wang, 2012). The IR absorption bands of citrate are not found in the PCC product prepared by calcium citrate complex (Figure $3 \mathrm{~b}$ and $3 \mathrm{~d}$ ). Therefore, the citrate ions in the calcium citrate complex have not been included or absorbed to the PCC product. The citrate ions in the complex may be recovered during the preparation of PCC product by exchanging $\mathrm{Ca}^{2+}$ ions with $\mathrm{Na}^{+}$ions of $\mathrm{Na}_{2} \mathrm{CO}_{3}$ at the carbonation stage. Furthermore, the FTIR bands of sucrose are not found in the PCC prepared from calcium sucrate and hence the sucrose used is recoverable at the end of $\mathrm{CaCO}_{3}$ precipitation.

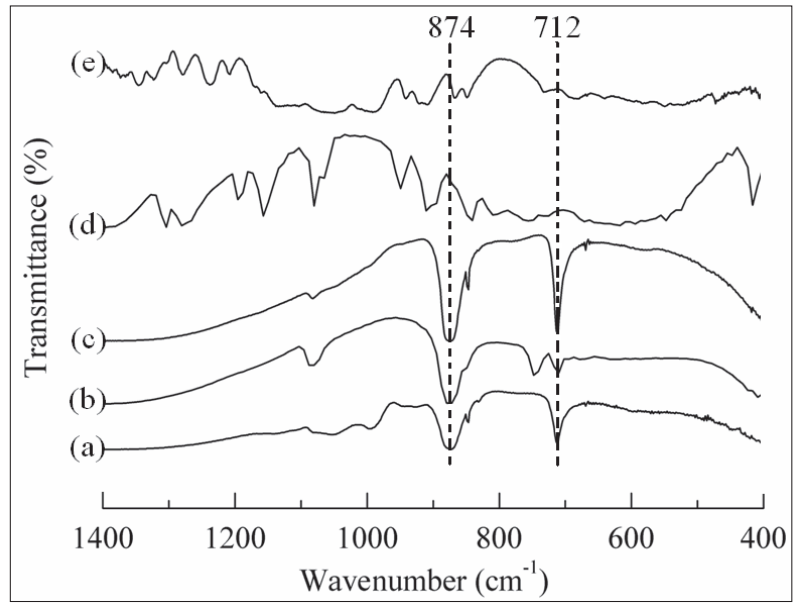

Figure 3: FTIR spectrum of PCC prepared from (a) a saturated solution of $\mathrm{Ca}(\mathrm{OH})_{2}$; (b) calcium citrate complex; (c) calcium sucrate; (d) trisodium citrate and (e) sucrose

\section{Industrials aspects of the devised methods}

The yields of PCC products prepared using saturated $\mathrm{Ca}(\mathrm{OH})_{2}$, calcium sucrate and calcium citrate are 71,78 and $24 \%$, respectively. The remaining part of calcium is present in the precipitate obtained during the preparation of these extracts. Although the yield of PCC prepared from saturated $\mathrm{Ca}(\mathrm{OH})_{2}$ is high, the productivity is very low, which is about $1.34 \mathrm{~g}$ of PCC that can be prepared using $1 \mathrm{~L}$ of aqueous saturated $\mathrm{Ca}(\mathrm{OH})_{2}$ solution. Therefore, this method is not suitable for industrial scale production of PCC. However, about $33.20 \mathrm{~g}$ of PCC can be prepared from $1 \mathrm{~L}$ of $0.50 \mathrm{M}$ calcium sucrate solution, which is a better productivity for industrial purposes. Moreover, in the calcium sucrate method, sucrose is recoverable after precipitating PCC. Therefore, the recovered sucrose is reusable to synthesize PCC to devise a continuous production process. As a result, the use of calcium sucrate is the best option to synthesize PCC and their nanoparticles from dolomitic marbles. As such, we have further characterized the PCC nanoparticles prepared from calcium sucrate using SEM and TGA and the corresponding results are given in Figure 4.

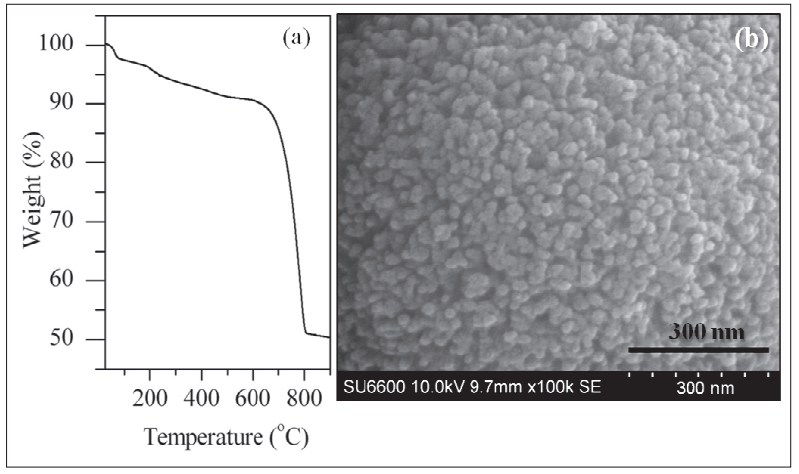

Figure 4: (a) TGA plot and (b) SEM image of PCC nanoparticles prepared from calcium sucrate

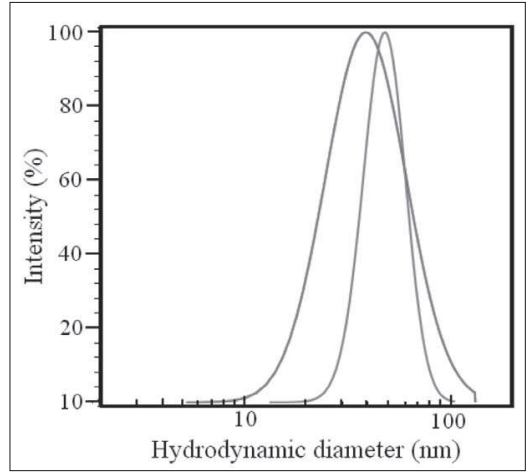

Figure 5: Particle size distribution curves of PCC nanoparticles prepared from calcium sucrate 
The TGA plot of PCC synthesized by calcium sucrate depicted in Figure 4 (a), shows a single-step decomposition in the temperature range $724-806{ }^{\circ} \mathrm{C}$, which gives a mass loss of $41 \%$ that can be attributed to the decomposition of $\mathrm{CaCO}_{3}$ to $\mathrm{CaO}$ and $\mathrm{CO}_{2}$ (Wang et al., 1999). Other than the $\mathrm{CaCO}_{3}$ decomposition curve in the TGA, there are two mass losses at the temperature ranges of $41-84{ }^{\circ} \mathrm{C}$ and $174-226{ }^{\circ} \mathrm{C}$, which can be attributed to the removal of physically and chemically bound water of the PCC product, respectively (Mantilaka et al., 2013b). However, the total mass loss due to the removal of water is approximately $3 \%$. Since the surface area of a nanoparticle is high, water molecules can easily be adsorbed on to the surface of PCC nanoparticles during preparation (Mantilaka et al., 2014a). Therefore, the presence of physically bound water is possible in PCC nanoparticles. The SEM image of the PCC product shown in Figure 4 (b) confirms that the particles are in spherical morphology with low particle aggregation. Also, the SEM image confirms the presence of particles in nanometer scale with the average particle size around $40 \mathrm{~nm}$. The particle sizes of PCC synthesized from calcium sucrate are further analyzed with the help of DLS particle size analysis. There are two particle size distribution curves for PCC nanoparticles prepared from calcium sucrate as shown in Figure 5. The mean particle sizes of PCC nanoparticles based on these two size distribution curves are 38.9 and $51.6 \mathrm{~nm}$. Therefore, it is further confirmed that the particles are in nanometer scale.

\section{CONCLUSION}

Sri Lankan dolomitic marbles can be used to synthesize PCC nanoparticles with high purity. The extraction of calcium components of calcined dolomite to sucrose is the best way for the preparation of PCC nanoparticles. Surfactants can be used to prevent the particle aggregation during the preparation of PCC nanoparticles using calcium sucrate. The sucrate ions stabilize calcite in the conditions favourable for aragonite. The synthesis of PCC nanoparticles for use in local industries and for the export market is a good method to add a very high value to the Sri Lankan dolomitic marbles.

\section{Acknowledgment}

The authors acknowledge the financial assistance by the National Research Council (Grant No. 11-178), Sri Lanka. We thank Ms N.I. Attanayake and $\mathrm{Mr}$ Mahinda Paranawitharana, Technical Officers of the Department of Chemistry, University of Peradeniya, for their technical assistance. We are grateful to both referees for their highly constructive comments and suggestions to improve the manuscript.

\section{REFERENCES}

1. Cooray P.G. (1984). An Introduction to the Geology of Sri Lanka (Ceylon), $2^{\text {nd }}$ edition, pp. $81-104,183-188$. National Museum, Colombo.

2. El-Sheikh S.M., El-Sherbiny S., Barhoum A. \& Deng Y. (2013). Effects of cationic surfactant during the precipitation of calcium carbonate nano-particles on their size, morphology, and other characteristics. Colloids Surfaces A 422: 44 - 49.

DOI: http://dx.doi.org/10.1016/j.colsurfa.2013.01.020

3. Feng B., Yong A.K. \& An H. (2007). Effect of various factors on the particle size of calcium carbonate formed in a precipitation process. Materials Science and Engineering A 445 - 446: 170 - 179 .

4. Jeffery G.H., Bassett J., Mendham J. \& Denney R.C. (1989). Vogel's Text Book of Quantitative Chemical Analysis, p. 58. Longman Group UK Limited, Essex, UK.

5. Karatas H., Olgun H. \& Akgun F. (2013). Coal and coal and calcined dolomite gasification experiments in a bubbling fluidized bed gasifier under air atmosphere. Fuel Processing Technology 106: 666 - 672.

DOI: http://dx.doi.org/10.1016/j.fuproc.2012.09.063

6. Kim J.A., Han G., Lim M., You K. \& Ryu M. (2009). Effect of hydraulic activity on crystallization of precipitated calcium carbonate (PCC) for eco-friendly paper. International Journal of Molecular Science 10: 4954 - 4962. DOI: http://dx.doi.org/10.3390/ijms10114954

7. Konopacka-Łyskawa D. \& Lackowski M. (2011). Influence of ethyleneglycol on $\mathrm{CaCO}_{3}$ particles formation via carbonation in the gas-slurry system. Journal of Crystal Growth 321: 136 - 141.

DOI: http://dx.doi.org/10.1016/j.jcrysgro.2011.02.018

8. Kuang D., Xu A., Fang Y., Ou H. \& Liu H. (2002). Preparation of inorganic salts $\left(\mathrm{CaCO}_{3}, \mathrm{BaCO}_{3}, \mathrm{CaSO}_{4}\right)$ nanowires in the triton $\mathrm{X}-100 /$ cyclohexane/water reverse micelles. Journal of Crystal Growth 244: 379 - 383. DOI: http://dx.doi.org/10.1016/S0022-0248(02)01684-6

9. Leeuwenburgh S.C.G., Ana I.D. \& Jansen J.A. (2010). Sodium citrate as an effective dispersant for the synthesis of inorganic-organic composites with a nanodispersed mineral phase. Acta Biomaterialia 6: 836 - 844 .

DOI: http://dx.doi.org/10.1016/j.actbio.2009.09.005

10. Li C., Li G., Liu S., Bai J. \& Zhang A. (2010). Spherical hydroxyapatite with colloidal stability prepared in aqueous solutions containing polymer/surfactant pair. Colloids and Surfaces A 366: 27 - 33 .

DOI: http://dx.doi.org/10.1016/j.colsurfa.2010.05.018

11. Madugalla T.B.N.S., Pitawala H.M.T.G.A. \& Karunaratne D.G.G.P. (2013). Petrographic and geochemical characteristics of marbles in Central Sri Lanka; potential applications in industries. Proceedings of the $29^{\text {th }}$ Technical Sessions of the Geological Society of Sri Lanka, 22 February, Institute of Fundermental Studies, Kandy, pp. $61-64$.

12. Mantilaka M.M.M.G.P.G., Pitawala H.M.T.G.A., Rajapakse R.M.G. \& Karunaratne D.G.G.P. (2013a). Nanomaterials from Sri Lankan marbles: a novel approach for value added products. Proceedings of the $29^{\text {th }}$ Technical Sessions of the 
Geological Society of Sri Lanka, 22 February, Institute of Fundermental Studies, Kandy, pp. 105 - 108.

13. Mantilaka M.M.M.G.P.G., Karunaratne D.G.G.P., Rajapakse R.M.G. \& Pitawala H.M.T.G.A. (2013b). Precipitated calcium carbonate/poly(methyl methacrylate) nanocomposite using dolomite: synthesis, characterization and properties. Powder Technology 235: 628 - 632 .

DOI: http://dx.doi.org/10.1016/j.powtec.2012.10.048

14. Mantilaka M.M.M.G.P.G., Rajapakse R.M.G., Karunaratne D.G.G.P. \& Pitawala H.M.T.G.A. (2014a). Preparation of amorphous calcium carbonate nanoparticles from impure dolomitic marble with the aid of poly (acrylic acid) as a stabilizer. Advanced Powder Technology 25(2): 591 - 598. DOI: http://dx.doi.org/10.1016/j.apt.2013.09.008

15. Mantilaka M.M.M.G.P.G., Pitawala H.M.T.G.A., Karunaratne D.G.G.P. \& Rajapakse R.M.G. (2014b). Nanocrystalline magnesium oxide from dolomite via poly(acrylate)stabilized magnesium hydroxide colloids. Colloids and Surfaces A 443: 201 - 208.

DOI: http://dx.doi.org/10.1016/j.colsurfa.2013.11.020

16. Muñoz-Espí R., Weiss C.K. \& Landfester K. (2012). Inorganic nanoparticles prepared in miniemulsion. Current Opinion in Colloid and Interface Science 17: 212 - 224. DOI: http://dx.doi.org/10.1016/j.cocis.2012.04.002

17. Park W.K., Ko S.J., Lee S.W., Cho K.H., Ahn J.W. \& Han C. (2008). Effects of magnesium chloride and organic additives on the synthesis of aragonite precipitated calcium carbonate. Journal of Crystal Growth 310: 2593 - 2601. DOI: http://dx.doi.org/10.1016/j.jcrysgro.2008.01.023

18. Periago A.M.L., Pacciani R., González C.G., Vega L.F. \& Domingo C. (2010). A breakthrough technique for the preparation of high-yield precipitated calcium carbonate. The Journal of Supercritical Fluids 52: $298-305$. DOI: ttp://dx.doi.org/10.1016/j.supflu.2009.11.014

19. Pitawala A., Schidlowski M., Dahanayake K. \& Hofmeister W. (2003). Geochemical and petrological characteristics of Eppawala phosphate deposits, Sri Lanka. Mineralium Deposita 38: $505-515$.

DOI: http://dx.doi.org/10.1007/s00126-002-0327-y

20. Price G.J., Mahon M.F., Shannon J. \& Cooper C. (2011). Composition of calcium carbonate polymorphs precipitated using ultrasound. Crystal Growth and Design 11: $39-44$.

DOI: http://dx.doi.org/10.1021/cg901240n

21. Rabaha M. \& Ewais E.M.M. (2009). Multi-impregnating pitch-bonded Egyptian dolomite refractory brick for application in ladle furnaces. Ceramics International 35: $813-819$.

DOI: http://dx.doi.org/10.1016/j.ceramint.2008.02.017

22. Samtani M., Dollimorey D., Wilburn F.W. \& Alexander K. (2001). Isolation and identification of the intermediate and final products in the thermal decomposition of dolomite in an atmosphere of carbon dioxide. Thermochimica Acta 367: $285-295$.

DOI: http://dx.doi.org/10.1016/S0040-6031(00)00662-6

23. Sarkar A. \& Mahapatra S. (2010). Synthesis of all crystalline phases of anhydrous calcium carbonate. Crystal Growth and Design 10: 2129 - 2135 .

DOI: http://dx.doi.org/10.1021/cg9012813
24. Seil G.E. (1943). Study of literature on separation of magnesia from lime in dolomite and similar materials. Journal of American Ceramic Society 26: 218 - 238. DOI: http://dx.doi.org/10.1111/j.1151-2916.1943.tb15823.x

25. Senarathna K.G.C., Mantilaka M.M.M.G.P.G., Peiris T.A.N., Pitawala H.M.T.G.A., Karunaratne D.G.G.P. \& Rajapakse R.M.G. (2014). Convenient routes to synthesize uncommon vaterite nanoparticles and the nanocomposites of alkyd resin/polyaniline/vaterite: the latter possessing superior anticorrosive performance on mild steel surfaces. Electrochimica Acta 117: 460 - 469.

DOI: http://dx.doi.org/10.1016/j.electacta.2013.11.137

26. Sommerdijk N.A.J.M. \& de With G. (2008). Biomimetic $\mathrm{CaCO}_{3}$ mineralization using designer molecules and interfaces. Chemical Reviews 108: 4499 - 4550.

DOI: http://dx.doi.org/10.1021/cr078259o

27. Sun Y., Jiang J., Kantarelis E., Xu J., Li L., Zhao S. \& Yang W. (2012). Development of a bimetallic dolomite based tar cracking catalyst. Catalysis Communications 20: 36 - 40. DOI: http://dx.doi.org/10.1016/j.catcom.2011.12.040

28. Varela J.J., Petter C.O. \& Wotruba H. (2006). Product quality improvement of Brazilian impure marble. Minerals Engineering 19: 355 - 363.

DOI: http://dx.doi.org/10.1016/j.mineng.2005.10.009

29. Wang C., Shao J., Shao H., Bala H. \& Wang Z. (2006). Synthesis of nanosized calcium carbonate (aragonite) via a polyacrylamide inducing process. Powder Technology 163: $134-138$.

DOI: http://dx.doi.org/10.1016/j.powtec.2005.12.019

30. Wang H., Huang W. \& Han Y. (2013). Diffusion-reaction compromise the polymorphs of precipitated calcium carbonate. Particuology 11: $301-308$.

DOI: http://dx.doi.org/10.1016/j.partic.2012.10.003

31. Wang L., Sondi I. \& Matijevic E. (1999). Preparation of uniform needle-like aragonite particles by homogeneous precipitation. Journal of Colloids and Interface Science 218: $545-553$.

DOI: http://dx.doi.org/10.1006/jcis.1999.6463

32. Westin K.J. \& Rasmuson A.C. (2005a). Crystal growth of aragonite and calcite in presence of citric acid, DTPA, EDTA and pyromellitic acid. Journal of Colloid and Interface Science 282: 359 - 369.

DOI: http://dx.doi.org/10.1016/j.jcis.2004.03.029

33. Westin K.J. \& Rasmuson A.C. (2005b). Nucleation of calcium carbonate in presence of citric acid, DTPA, EDTA and pyromellitic acid. Journal of Colloid and Interface Science 282: 370 - 379.

DOI: http://dx.doi.org/10.1016/j.jcis.2004.09.071

34. Westin K.J. \& Rasmuson H.C. (2003). Precipitation of calcium carbonate in the presence of citrate and EDTA. Desalination 159: $107-118$.

DOI: http://dx.doi.org/10.1016/S0011-9164(03)90063-4

35. Wu Y., Anthony E.J., Wang J. \& Jia L. (2007). Simultaneous hydration/carbonation of FBC ash by low-frequency sonication. Chemical Engineering and Processing 47: $9-16$. DOI: http://dx.doi.org/10.1016/j.cep.2007.08.002

36. Xiang L., Xiang Y., Wang Z.G. \& Jin Y. (2002). Influence of chemical additives on the formation of super-fine calcium 
carbonate. Powder Technology 126: 129 - 133.

DOI: http://dx.doi.org/10.1016/S0032-5910(02)00047-5

37. Yamanaka S., Ito N., Akiyama K., Shimosaka A., Shirakawa Y. \& Hidaka J. (2012). Heterogeneous nucleation and growth mechanism on hydrophilic and hydrophobic surface. Advanced Powder Technology 23: 268 - 272. DOI: http://dx.doi.org/10.1016/j.apt.2012.01.002

38. Yao L., Yang J., Sun J., Cai L., He L., Huang H., Song R. \& Hao Y. (2011). Hard and transparent hybrid polyurethane coatings using in situ incorporation of calcium carbonate nanoparticles. Materials Chemistry and Physics 129: $523-528$.
DOI: http://dx.doi.org/10.1016/j.matchemphys.2011.04.066

39. Zhang Y.F., Zhang J.X., Lu Q.M. \& Zhang Q.Y. (2006). Synthesis and characterization of $\mathrm{Ca}_{3} \mathrm{Co}_{4} \mathrm{O}_{9}$ nanoparticles by citrate sol-gel method. Materials Letters 60: $2443-$ 2446.

DOI: http://dx.doi.org/10.1016/j.matlet.2006.01.013

40. Zhao L. \& Wang J. (2012). Biomimetic synthesis of hollow microspheres of calcium carbonate crystals in the presence of polymer and surfactant. Colloids and Surfaces A 393: $139-143$.

DOI: http://dx.doi.org/10.1016/j.colsurfa.2011.11.012 